ORIGINAL PROF-2105

\title{
SUBCLINICAL HYPOTHYROIDISM;
}

Frequency in chronic kidney disease patients before dialysis.

Dr. Mohammad Asif, Mr. Atif Ullah, Mr. Muhammad Akram

ABSTRACT... Chronic kidney disease (CKD) is characterized by progressive destruction of renal mass with irreversible sclerosis and loss of nephrons. Various metabolic, hematological and endocrine abnormalities are known to occur in CKD. Subclinical hypothyroidism is an important endocrine abnormality associated with a greater cardiovascular risk, atherosclerosis and an important factor for progression of renal disease in such patients. Objective: To calculate the frequency of subclinical hypothyroidism in predialysis CKD patients. Design: Cross sectional survey. Setting: Pathology Department Post Graduate Medical Institute, Lahore. Period: 06 months (June 2011 to Dec 2011). Results: 210 patients were included in the study. Serum creatinine. TSH and FT4 were measured and the relevant data was entered in predesigned proforma. $19.5 \%$ of CKD population had subclinical hypothyroidism with slightly increased preponderance in females as compared to males and also increased frequency as the stage of CKD increased. Subclinical hypothyroidism is more common in CKD population. Conclusions: Increased frequency of subclinical hypothyroidism was found in patients with reduced renal function not on dialysis. 19.5\% of CKD population on conservative management had labortary evidence of thyroid dysfunction.

Key words: Chronic kidney disease, subclinical hypothyroidism

\section{Article Citation}

$\checkmark \quad$ Asif M, Atif Ullah, Akram M. Frequency of subclinical hypothyroidism in chronic kidney disease patients before dialysis. Professional Med J Feb 2013;20(1):023-029.

\section{INTRODUCTION}

Chronic kidney disease (CKD) is defined as kidney damage or glomerular filtration rate $<60 \mathrm{ml} / \mathrm{min} /$ $1.73 \mathrm{~m}^{2}$ for 3 months or more irrespective of the cause. Glomerular filtration rate can be estimated from serum creatinine by equation like the Cockcroft-Gault formula. Kidney disease severity is classified into five stages according to the level of glomerular filtration rate $^{1}$. Chronic kidney disease is accompanied by notable effects on the hypothalamic-pituitary thyroid axis. The secretion of pituitary thyrotrophin is impaired in uremia ${ }^{2}$. The kidney is an important target organ of thyroid hormone action. Renal function is influenced by both hypothyroidism and hyperthyroidism. Renal function improved significantly during treatment of hypothyroidism and decreased during treatment of hyperthyroidism. There is strong relationship between the change in thyroid status and change in the renal function ${ }^{3}$.

Certain effects of the hypothyroid state on the kidney are well established. Physiological effects include changes in water and electrolyte metabolism, notably hypoatremia and reliable alterations of renal hemodynamic, including decrements in renal blood flow, renal plasma flow, glomerular filtration rate and single nephron GFR. The cause of the decreased renal plasma flow and glomerular filtration rate observed is believed to be principally due to the generalized hypodynamic state of the circulatory system in hypothyroidism ${ }^{4}$.

Hypothyroidism reduces and hyperthyroidism increases the kidney to body weight ratio. The most common derangements associated to hypothyroidism are elevation of serum creatinine levels, reduction in glomerular filtration rate and renal plasma flow. Thyrotoxicosis is characterized by an increase in renal plasma flow and glomerular filtration rate in reduction of serum creatinine level. Hyperthyroidism may be linked to a decrease in total body water and exchangeable potassium².

Among a nationally representative sample of adults decrease in glomerular filtration rate was associated with a higher prevalence of hypothyroidism with many 
subclinical cases ${ }^{5}$. It has been suggested that primary hypothyroidism may be more common in patients with end stage renal disease compared with general population. Along with this thyroid hormone abnormalities have been reported among euthyroid patients with end stage renal disease including reduced total and free triiodotyronine and thyroxine levels. Reasons for these findings are unclear but it may be due to an adaptive response to chronic non thyroid illness, unresolved uremia and protein malnutrition ${ }^{5}$. Patients with chronic kidney disease have an increased thyroid volume compared with normal renal function and a higher occurrence of goiter mainly in women. Thyroid nodule and thyroid carcinoma are more common in uremic patients than in the general population ${ }^{2}$. Subclinical hypothyroidism has been associated with cardiovascular risk and cardiac impairment. The most recent national health and nutrition examination surveys showed that the prevalence of chronic kidney disease increased from $10.1 \%$ in $1988-1994$ to $13.1 \%$ in $1999-2004^{6}$.

The decline of kidney function is accompanied by changes in synthesis, secretion, metabolism and elimination of thyroid hormones. Thyroid dysfunction acquires special characteristics in those patients with advanced kidney disease. Both thyroid and kidney functions are affected by the different treatments used in the management of patients with kidney and thyroid diseases. 2 The cause of the decreased renal plasma flow and glomerular filtration rate is believed to be principally due to generalized hypodynamic state of the circulatory system in hypothyroidism ${ }^{4}$.

In patients with end stage renal disease a variety of alterations in thyroid hormone levels and metabolism have been described. Low level of plasma triiodothyronine has been consistently found to be the most common disturbance in thyroid function? ${ }^{7}$. Patients with non-thyroid illness (NTI) frequently have changes in serum levels of thyroid hormones that may suggest thyroid dysfunction. Many of the clinically euthyroid patients with non-thyroid illness have low circulating concentration of total and absolute $\mathrm{T} 3$, low or normal concentration of T4, elevated concentration of absolute free T4 and normal or subnormal levels of thyroid stimulating hormone. Patients with chronic kidney disease as an example of non-thyroid illness and the degree of thyroid dysfunction correlate with the severity of kidney damage.

Chronic kidney disease causes alteration in thyroid hormones in the absence of an underlying intrinsic thyroid disorder, characterized by a decrease in total T3 and free T3 plasma concentration whilst thyroid stimulating hormone level are usually normal ${ }^{9,10}$. Chronic kidney disease is associated with multiple disturbances in thyroid hormone metabolism that are manifested low serum free and total T3 levels and normal rT3 and free T4 concentrations. The serum thyroid stimulating hormone concentration is normal and most patients are euthyroid ${ }^{11,12}$.

Various studies to diagnose the magnitude of the problem have been done throughout the world both in pre dialysis CKD and End Stage Renal Disease (ESRD) patients and the estimated statistics ranges between 15-20 in different studies in different populations. The study is designed to measure the magnitude of problem in our population.

\section{MATERIALS AND METHODS}

The study was carried out in pathology department Post Graduate Medical institute Lahore. The duration of study was six months and sample size was 210 chronic kidney disease patients. Non probability purposive sampling technique was used. All adults' chronic kidney disease patients 18-80 years in different stages were included in the study. Patients with acute renal failure, pregnant, any thyroid illness and post dialysis patients were excluded.

After informed consent, venous blood samples were taken from the patients for the measurement of serum 
Creatinine, free thyroxin (FT4) and thyroid stimulating hormone (TSH). Serum Creatinine was measured by enzymatic method through Jaffe kinetic reaction reported by Larsen. TSH and T4 were measured by commercially prepared ELISA kits according to manufacturer' instructions (Biochek USA). Data for reporting was analyzed by softmax pro software using V max from Nova biolab as plate reader. All informations obtained from the patients were recorded on the predesigned Performa.

Data was analyzed by computer software SPSS (version 16). The quantitative variables like age were presented in the mean and standard deviations while qualitative variables like sex and the presence of subclinical hypothyroidism were recorded in frequencies/percentages.

\section{RESULTS}

A total of 210 patients were included in the study. The mean age was $44.7 \pm 16.5$ years with 100 female patients (47.6\%) and 110 men (52.4\%) (Table I, Figure 1). Most of the patients were in stage 5 i.e. $(57.1 \%$ of the total) having GFR was less than $15 \mathrm{ml} / \mathrm{min} / 1.73 \mathrm{~m}^{2}$,
52 patients were in stage 4 (24.8\%) and 38 (18.1\%) in stage 3 and all patients GFR was less than 60 $\mathrm{ml} / \mathrm{min} / 1.73 \mathrm{~m}^{2}$ (Table Il).

The mean value of serum TSH and FT4 concentrations were $4.1 \mathrm{mlU} / \mathrm{L}$ (range $0.8-3 \mathrm{mlU} / \mathrm{L}$ and FT4 $17.4 \pm$ $3.9 \mathrm{pmol} / \mathrm{L}$ (range $11-24 \mathrm{pmol} / \mathrm{L}$ ), respectively. Most of the patients $(n=169,80.5 \%)$ serum thyroid functions tests were within reference range whereas $19.5 \%(n=41)$ TSH $>3 \mathrm{~m} \mathrm{IU} / \mathrm{L}$ with normal FT4 level and $5.23 \%(n=11)$ TSH $<0.8 \mathrm{~m} \mathrm{IU} / \mathrm{L}$ with normal FT4 level. These values suggest dysfunction of thyroid function tests representing subclinical hypothyroidism and subclinical biochemical hyperthyroidism respectively (Table-II). All the 210 patients GFR was less than $60 \mathrm{ml} / \mathrm{min} / 1.73 \mathrm{~m} 2$, none of them required dialytic therapy.

\section{DISCUSSION}

Among our sample of adults patients aged 18-80 years, an increased frequency of subclinical hypothyroidism in persons with reduced estimated GFR, there was slightly increased trend with increasing age, female gender. In addition, with progressively

\begin{tabular}{|c|c|c|c|c|c|}
\hline & & & \multicolumn{2}{|l|}{ SCH } & \multirow[b]{2}{*}{ Total } \\
\hline & & & Subclinical Hypothyroidism & Euthyroidism & \\
\hline Sex & Female & $\begin{array}{l}\text { Cont } \\
\% \text { within sex } \\
\% \text { within SCH } \\
\% \text { of total }\end{array}$ & $\begin{array}{c}22 \\
22.0 \% \\
53.7 \% \\
10.5 \%\end{array}$ & $\begin{array}{c}78 \\
78.0 \% \\
46.2 \% \\
37.1 \%\end{array}$ & $\begin{array}{c}100 \\
100.0 \% \\
47.6 \% \\
47.65 \%\end{array}$ \\
\hline & Male & $\begin{array}{l}\text { Cont } \\
\% \text { within sex } \\
\% \text { within SCH } \\
\% \text { of total }\end{array}$ & $\begin{array}{c}19 \\
17.3 \% \\
46.3 \% \\
9.0 \%\end{array}$ & $\begin{array}{c}91 \\
82.7 \% \\
53.8 \% \\
43.3 \%\end{array}$ & $\begin{array}{c}110 \\
100.0 \% \\
52.4 \% \\
52.4 \%\end{array}$ \\
\hline Total & & $\begin{array}{l}\text { Count } \\
\% \text { within sex } \\
\% \text { within } \mathrm{SCH} \\
\% \text { of total }\end{array}$ & $\begin{array}{c}41 \\
19.5 \% \\
100.0 \% \\
19.5 \%\end{array}$ & $\begin{array}{c}169 \\
80.5 \% \\
100.0 \% \\
80.5 \%\end{array}$ & $\begin{array}{c}210 \\
100.0 \% \\
100.0 \% \\
100.0 \%\end{array}$ \\
\hline
\end{tabular}




\begin{tabular}{|c|c|c|c|c|}
\hline & & \multicolumn{2}{|l|}{ SCH } & \multirow[b]{2}{*}{ Total } \\
\hline & & Subclinical Hypothyroidism & Euthyroidism & \\
\hline Stage 3 & $\begin{array}{l}\text { Cont } \\
\% \text { within stage } \\
\% \text { within SCH } \\
\% \text { of total }\end{array}$ & $\begin{array}{c}7 \\
18.4 \% \\
17.4 \% \\
3.3 \%\end{array}$ & $\begin{array}{c}31 \\
81.6 \% \\
18.3 \% \\
14.8 \%\end{array}$ & $\begin{array}{c}38 \\
100.0 \% \\
18.1 \% \\
18.1 \%\end{array}$ \\
\hline Stage 4 & $\begin{array}{l}\text { Cont } \\
\% \text { within stage } \\
\% \text { within SCH } \\
\% \text { of total }\end{array}$ & $\begin{array}{c}9 \\
17.3 \% \\
22.0 \% \\
4.3 \%\end{array}$ & $\begin{array}{c}43 \\
82.7 \% \\
25.4 \% \\
20.5 \%\end{array}$ & $\begin{array}{c}52 \\
100.0 \% \\
24.8 \% \\
24.8 \%\end{array}$ \\
\hline Stage 5 & $\begin{array}{l}\text { Count } \\
\% \text { within stage } \\
\% \text { within SCH } \\
\% \text { of total }\end{array}$ & $\begin{array}{c}25 \\
20.8 \% \\
61.0 \% \\
11.9 \%\end{array}$ & $\begin{array}{c}95 \\
79.2 \% \\
56.2 \% \\
45.2 \%\end{array}$ & $\begin{array}{c}120 \\
100.0 \% \\
57.1 \% \\
57.1 \%\end{array}$ \\
\hline Total & $\begin{array}{l}\text { Count } \\
\% \text { within stage } \\
\% \text { within SCH } \\
\% \text { of total }\end{array}$ & $\begin{array}{c}41 \\
19.5 \% \\
100.0 \% \\
19.5 \%\end{array}$ & $\begin{array}{c}169 \\
80.5 \% \\
100.0 \% \\
80.5 \%\end{array}$ & $\begin{array}{c}210 \\
100.0 \% \\
100.0 \% \\
100.0 \%\end{array}$ \\
\hline
\end{tabular}

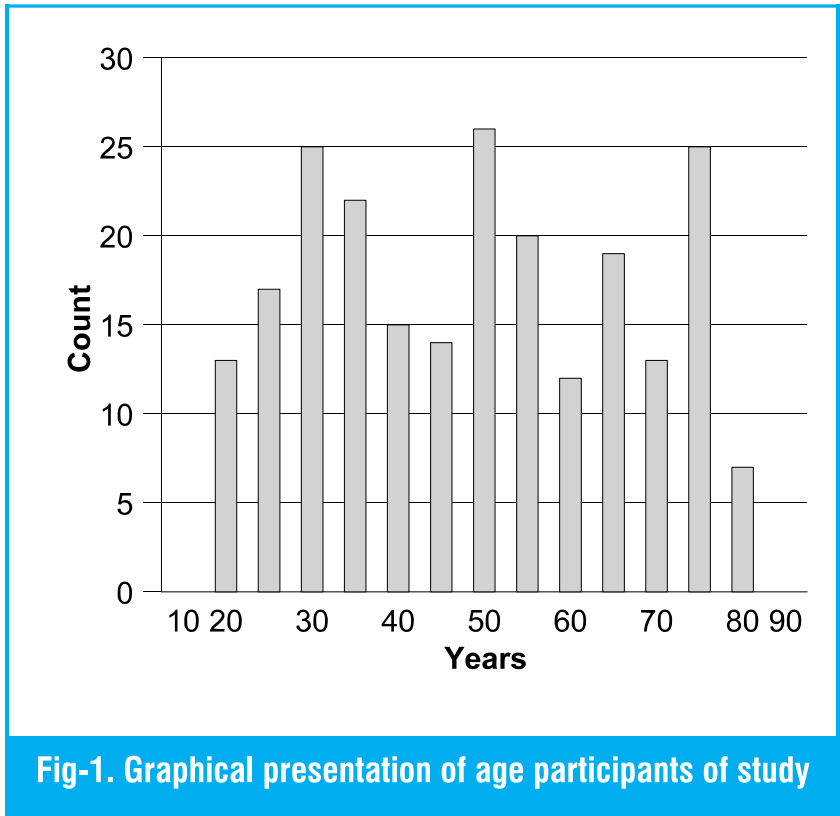

lower GFR, there was an increased likelihood of subclinical hypothyroidism.

Previous studies have suggested an increased prevalence of hypothyroidism in patients with ESRD requiring maintenance dialysis hemodialysis as well as peritoneal dialysis, and an increased prevalence of goiter. Only a few of the previous studies have examined the prevalence of hypothyroidism among patients with CKD not requiring dialysis. Bando et al in small group of patients with 32 diabetics and 31 nondiabetics nephropathy (urinary protein excretion greater than $0.5 \mathrm{~g} /$ day), $24 \%$ of study subjects had overt or subclinical hypothyroidism, with a higher prevalence among diabetics and non-diabetics patients, although most of the patients included in our study were diabetics and most of patients were in CKD stage $^{5}$.

Chonchol et al in their study which included 3089 adult participants found, $293(9.5 \%)$ had subclinical primary hypothyroidism and $277(9 \%)$ had an estimated GFR $<60 \mathrm{ml} / \mathrm{min} / 1.73 \mathrm{~m}^{2}$. The prevalence of subclinical hypothyroidism increased from $7 \%$ at an estimated GFR $90 \mathrm{ml} / \mathrm{min} / 1.73 \mathrm{~m}^{2}$ to $17.9 \%$ at an 
estimated GFR $<60 \mathrm{ml} / \mathrm{min} / 1.73 \mathrm{~m}^{2}$ ( $p<0.0001$ for trend).compared with participants with an estimated $60 \mathrm{ml} / \mathrm{min} / 1.73 \mathrm{~m}^{2}$, those with estimated GFR $<60$ $\mathrm{ml} / \mathrm{min} / 1.73 \mathrm{~m}^{2}$ had increased odds of subclinical hypothyroidism after adjusting for age, gender, fasting plasma glucose, total cholesterol and triglyceride concentrations $^{6}$. This was a large study which used data base and analyzed results. The study did not differentiate between those having abnormal function test with symptoms or those without symptoms. While our study excluded the patients with sign or symptoms of thyroid disease. However, our study did not adjust for age, gender, race, fasting glucose level, serum cholesterol level and serum triglycerides level.

In another study, Lo et al recently noticed increased prevalence of subclinical and clinical primary hypothyroidism at slightly lower levels of kidney function in a nationally representative cohort of U.S adults. Among these participants, more than $20 \%$ of those with GFR less than $60 \mathrm{ml} / \mathrm{min} / 1.77 \mathrm{~m}^{2}$ had clinical or subclinical primary hypothyroidism after controlling for age, gender, and race/ethnicity ${ }^{5}$. In contrast, our study included only subclinical cases, those having clinical signs and symptoms of thyroid insufficiency were excluded from study. The criterion for CKD was same as our study had. Our study did not adjust for the age, gender and ethnicity/race.

According to Hollowell and Papi in 2007, Subclinical hypothyroidism is most commonly caused by chronic autoimmune thyroiditis, which is typically characterized by a mild asymptomatic goiter with diffuse hypoechogenicity on thyroid ultrasound and by the presence of high titer of serum thyroid auto antibodies. Other less common causes of transient or permanent primary hypothyroidism include drug induced hypothyroidism, subacute thyroiditis, radiation thyrioditis and postpartum thyroiditis. Many patients with CKD have mild reductions in thyroid function, or subclinical hypothyroidism a condition that becomes more common as kidney function declines.

\section{CONCLUSIONS}

Increased frequency of subclinical hypothyroidism was found in patients with reduced renal function not on dialysis. $19.5 \%$ of CKD population on conservative management had labortary evidence of thyroid dysfunction.

\section{SUGGESTION}

Further studies are required to establish a causal and temporal relationship between CKD and thyroid insufficiency. Studies are also needed to explore the peritoneal benefits of screening CKD patients for subclinical hypothyroidism and possible role of the treatment to avoid cardiovascular risk.

\section{Limitations}

- $\quad$ This study has some weaknesses

- $\quad$ The study did not adjust for the race, blood glucose levels, serum cholesterol and serum triglycerides.

- $\quad$ The study was based on the estimation of GFR rather than more accurate methods to measure actual GFR.

- $\quad$ The study was cross sectional and limited in its ability to establish causual and temporal relationship between CKD and subclinical hypothyroidism.

- $\quad$ Other causes (thyroidal and non-thyroidal illnesses) of subclinical hypothyroidism were not identified.

\section{Advantages}

Despite the above weaknesses the study has several strengths

- $\quad$ Patients with co-existing thyroid illness, using antithyriod drugs and those having clinical signs and symptoms of thyroid were excluded from the study.

- $\quad$ Subclinical hypothyroidism was diagnosed according to widely accepted clinical criterion i-e. TSH and free T4 were used instead of total 
T4.

- $\quad$ The method used to measure thyroid functions was uniform.

- The study used hospitalized and nonhospitalized pre dialysis CKD patients and a single reading is likely to show the steady state of thyroid functions tests.

- The method used to measure thyroid functions was uniform.

- $\quad$ A large sample size was used in our study.

Copyright@ 19 Nov, 2012.

\section{REFERENCES}

1. Levey AS., Eckardt KU, Tsukamoto Y, Levin A, Coresh J, and Rosset, J. Definition and Classification of Chronic Kidney Disease: a positive statement from kidney disease: Improving Global Outcomes (KDIG0). Kidney Int 2005; 67(6):2089-100.

2. Iglesias $P$ and Diez JJ. Thyroid dysfunction and kidney disease. European journal of endocrinology 2009; (160):503-515.

3. Den Holland GJ, Wulkan WR, Mantel JM, and Berghout A. Correlation between severity of thyroid dysfunction and renal function. Clin Endocrinol (Oxf) 2005; 62(4):423-7.

4. Kreisman SH, and Hennessey VJ. Consistent Reversible Elevation of Serum Creatinine Levels in Severe Hypothyroidism. Arch Intern Med 1999; (159):79-82.

5. Lo JC, Chertow MG, Go AS and Hsu CY. Increased prevalence of subclinical and clinical hypothyroidism in persons with chronic kidney disease. Kidney international 2005; 67:1047-1052.

6. Chonchol M, Lippi G, Salvagno G, Zoppini G, Muggo M and Targher G. Prevalence of subclinical Hypothyridism in patients with Chronic kidney Disease. Clin J Am Nephrol 2008: (3);1296-1300.
7. Enia G, Panuccio V, Cntupi S, Pizzim P, Tripepi G and Mallamaci $F$ et al. Subclinical hypothyroidism is linked to microinflammation and predicts death in continuous ambulatory peritoneal dialysis. Dial Transplant 2007; (22):538-54.

8. Abozenah H, Shoeb S, Sabry A and Ismail H. Relation between thyroid hormonal concentration and serum levels of interleukin- 6 and interleukin-10 in patients with Non-thyroid illness including chronic kidney disease. IJKD 2008; (2):16-23.

9. Zoccalic C, Tripepi G, Cutrupi S, Pizzen P, Mallmaci F.2. Low tri-iodothyronine: A new facet of inflammation in End stage renal disease. J Am soc Nephrol 2005; 16:2789-2795.

10. Coresh J, Selvin E and Stevens LA. Prevalence of chronic kidney disease in the United States. JAM 2007; 298(17):2038-2047.

11. Palmer BF, Henrich WL. Thyroid function in chronic kidney disease.

12. Hosseinpanah F, Kasraei, F, Nassiri AA, and Azizi F. High prevalence of chronic kidney disease in iran: A large population based study. BMC Public health 2009; 9:44-52.

13. ELISA, 2010 Wikipedia, the free encyclopedia.

14. Tietz, et al., Clinical chemistry and molecular diagnostics. 4th ED 2006: 2065-207.

15. Bishop, ML et al. Clinical chemistry principles, procedures, correlation. $5^{\text {th }}$ ED: 220-227, 275-276.

16. Diagnostic automation, 2009. inc.www.rapidtest.com

17. Rongen, HA., Hoetelmans, RM., Bult, A., Van Bennekom, WP.1994. Enzyme linked immunosorbent assays. J pharm Biomed Anal 12(4):433-62.

18. Larsen, K. Creatinine assay by a reaction kinetic approach. Clin Chem Acta 1972 (41):209-17. 


\section{AUTHOR(S):}

1. DR. MOHAMMAD ASIF

MBBS, M.Phil

Pathology Department

Post Graduate Medical Institute Lahore, Pakistan

2. MR. ATIF ULLAH

M.Sc (Chemistry)

3. MR. MUHAMMAD AKRAM, M.Phil

Assistant Professor

Sheikh Zayed Medical College, Lahore

\section{CORRESPONDENCE ADDRESS:}

Dr. Mohammad Asif

Pathology Department

Post Graduate Medical Institute Lahore, Pakistan.

drasif555@yahoo.com

\section{PREVIOUS RELATED STUDIES}

Fatima Mehboob. SUB CLINICAL HYPOTHYROIDISM; SHOULD IT BE TREATED? (Original) Prof Med Jour 10(1) 48 - 50 Jan, Feb, Mar, 2003.

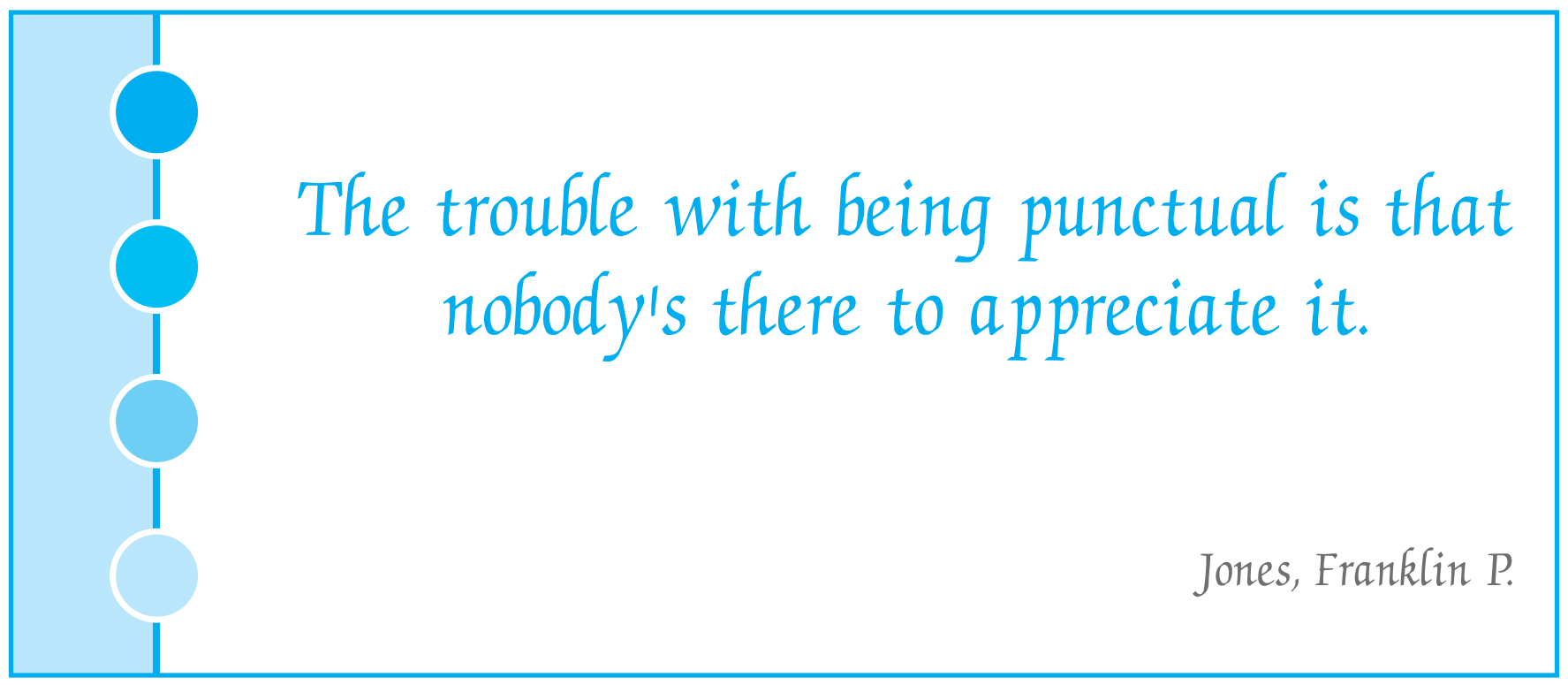

